Online supplementary material

Supplement 1

\begin{tabular}{|c|c|c|c|c|c|c|}
\hline Localities & Site number & Region & Province & Altitude (m a.s.1.) & U.T.M. X & U.T.M. Y \\
\hline Remondò (PV) & 1 & Lombardy & Pavia & 100 & 526925 & 5026471 \\
\hline Cergnago-S. Giorgio Lomellina (PV) & 2 & Lombardy & Pavia & 100 & 525316 & 5019176 \\
\hline Cameri, Cascina Bornago (NO) & 3 & Piedmont & Novara & 170 & 476905 & 5044778 \\
\hline Cameri, Cascina Bornago (NO) & 4 & Piedmont & Novara & 170 & 476880 & 5044781 \\
\hline Cameri, near the Ticino (NO) & 5 & Piedmont & Novara & 170 & 476898 & 5044731 \\
\hline Pombia, il Casone (NO) & 6 & Piedmont & Novara & 170 & 475131 & 5053637 \\
\hline Pombia, il Casone (NO) & 7 & Piedmont & Novara & 170 & 475380 & 5053673 \\
\hline Pombia, il Casone (NO) & 8 & Piedmont & Novara & 170 & 475364 & 5053676 \\
\hline Pombia, il Casone (NO) & 9 & Piedmont & Novara & 170 & 475136 & 5053648 \\
\hline Pombia, il Casone (NO) & 10 & Piedmont & Novara & 170 & 475398 & 5053669 \\
\hline Pombia, il Casone (NO) & 11 & Piedmont & Novara & 170 & 475167 & 5053641 \\
\hline Oleggio, Barbellera (NO) & 12 & Piedmont & Novara & 170 & 475343 & 5051376 \\
\hline Oleggio, Barbellera (NO) & 13 & Piedmont & Novara & 170 & 475332 & 5051342 \\
\hline Oleggio, Barbellera (NO) & 14 & Piedmont & Novara & 170 & 475299 & 5051385 \\
\hline Oleggio, Barbellera (NO) & 15 & Piedmont & Novara & 170 & 474960 & 5051991 \\
\hline Oleggio, Barbellera (NO) & 16 & Piedmont & Novara & 170 & 475180 & 5051636 \\
\hline Oleggio, Barbellera (NO) & 17 & Piedmont & Novara & 170 & 474944 & 5052074 \\
\hline Oleggio, Barbellera (NO) & 18 & Piedmont & Novara & 170 & 475302 & 5051402 \\
\hline Oleggio, Barbellera (NO) & 19 & Piedmont & Novara & 170 & 475157 & 5051479 \\
\hline Oleggio, Barbellera (NO) & 20 & Piedmont & Novara & 170 & 475277 & 5051386 \\
\hline Oleggio, Barbellera (NO) & 21 & Piedmont & Novara & 170 & 474953 & 5052032 \\
\hline Oleggio, Barbellera (NO) & 22 & Piedmont & Novara & 170 & 475175 & 5051647 \\
\hline Oleggio, Barbellera (NO) & 23 & Piedmont & Novara & 170 & 474972 & 5052028 \\
\hline Oleggio, Barbellera (NO) & 24 & Piedmont & Novara & 170 & 475208 & 5051435 \\
\hline Oleggio, Barbellera (NO) & 25 & Piedmont & Novara & 170 & 475308 & 5051370 \\
\hline Arborio (VC) & 26 & Piedmont & Vercelli & 120 & 474420 & 5076634 \\
\hline Greggio (VC) & 27 & Piedmont & Vercelli & 120 & 452870 & 5032615 \\
\hline Crevola (VC) & 28 & Piedmont & Vercelli & 450 & 457201 & 5132484 \\
\hline Locarno (VC) & 29 & Piedmont & Vercelli & 450 & 458490 & 5130653 \\
\hline
\end{tabular}

Italian studied sites: locality names, Region, Province, Altitude, Geographical Coordinates.

\title{
Supplement 2
}

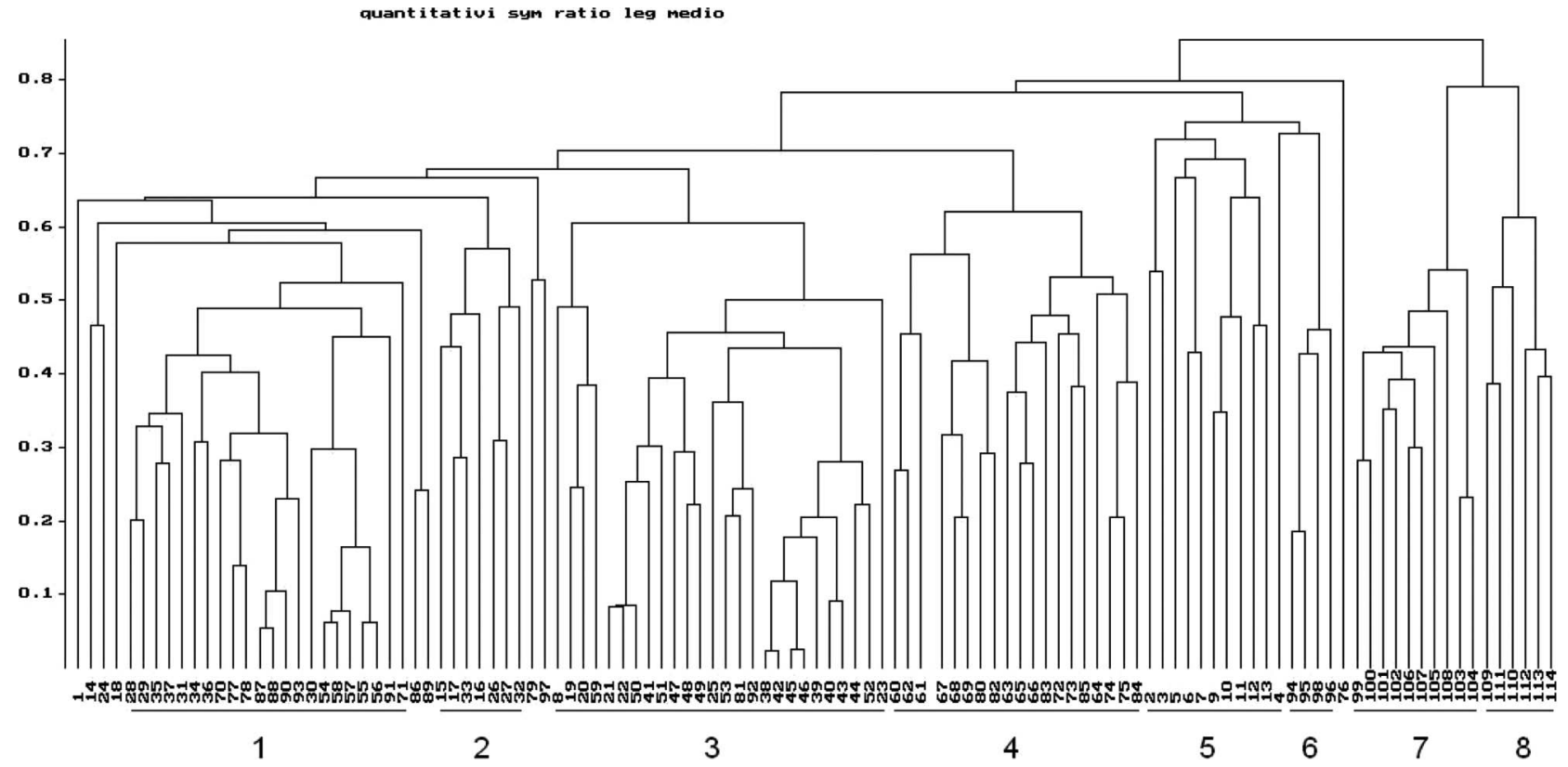

Dendrogram from cluster analysis (similarity ratio and UPGMA). 


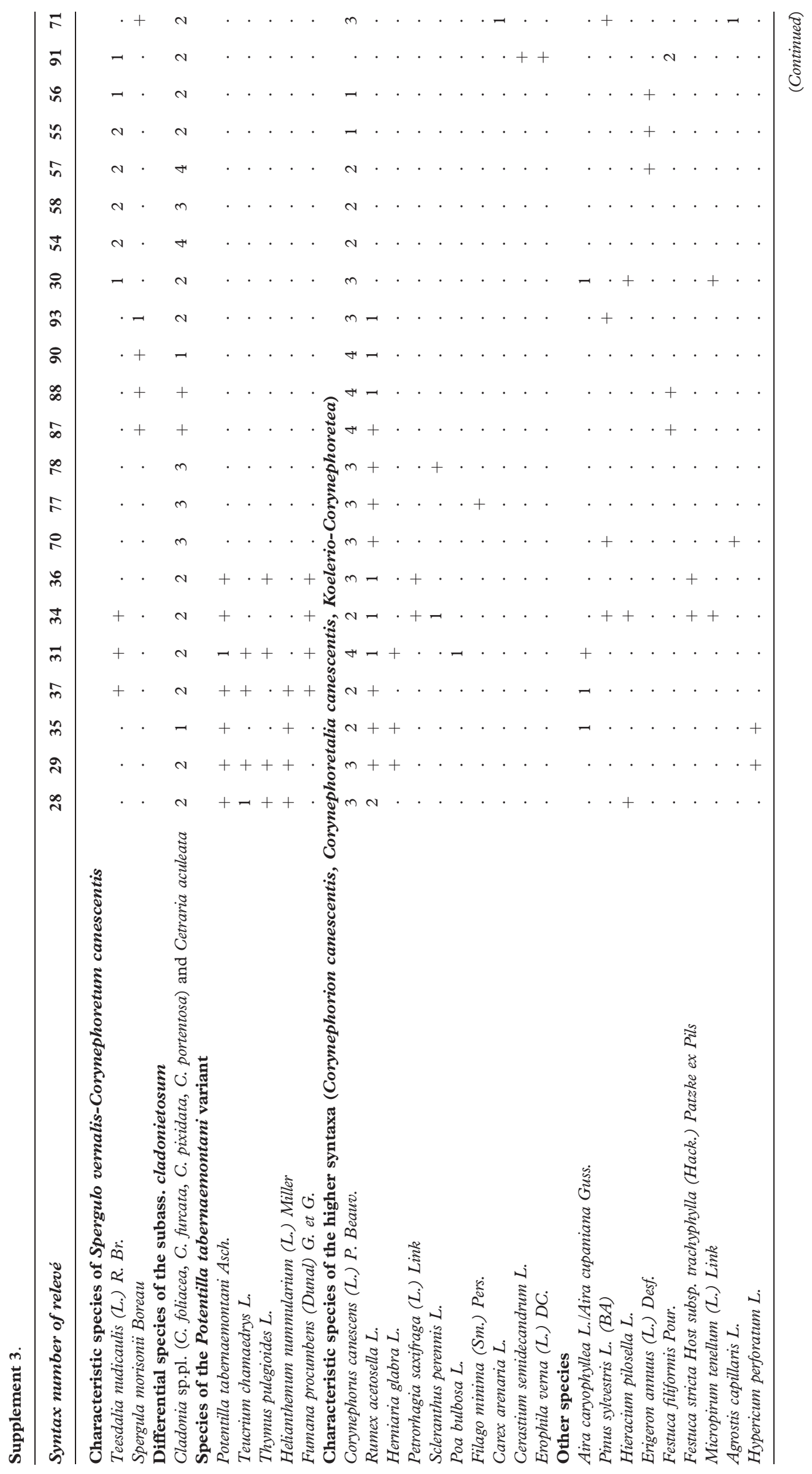




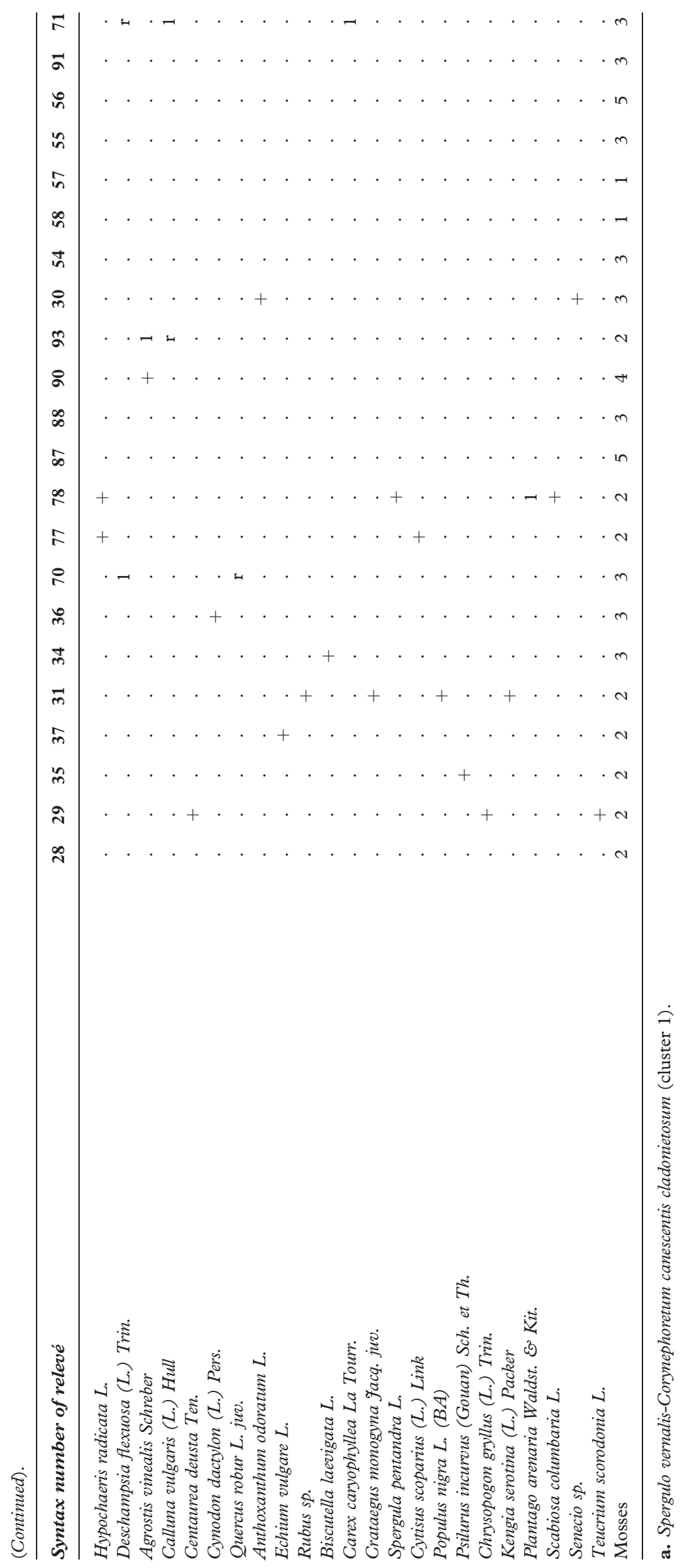




$$
\Delta
$$




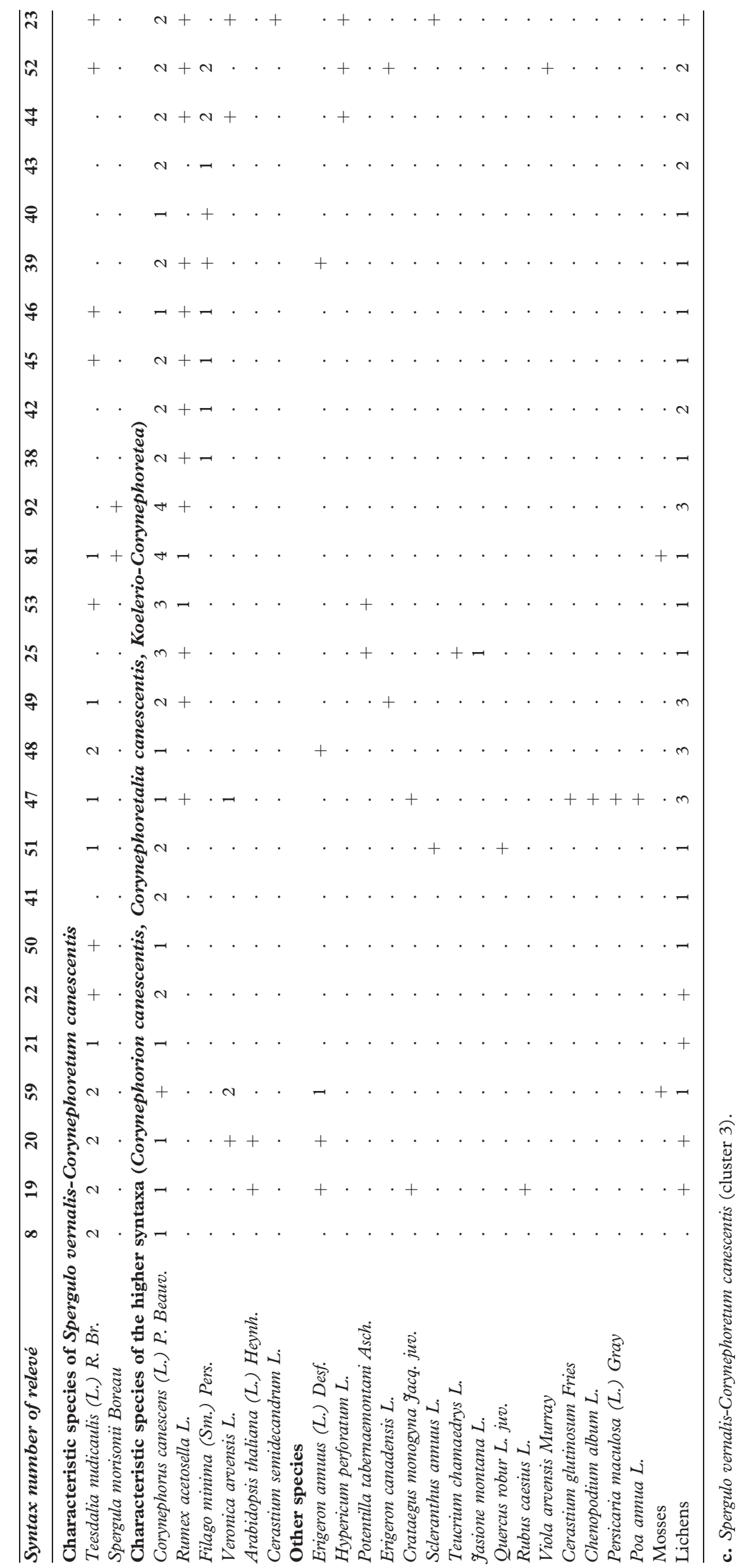




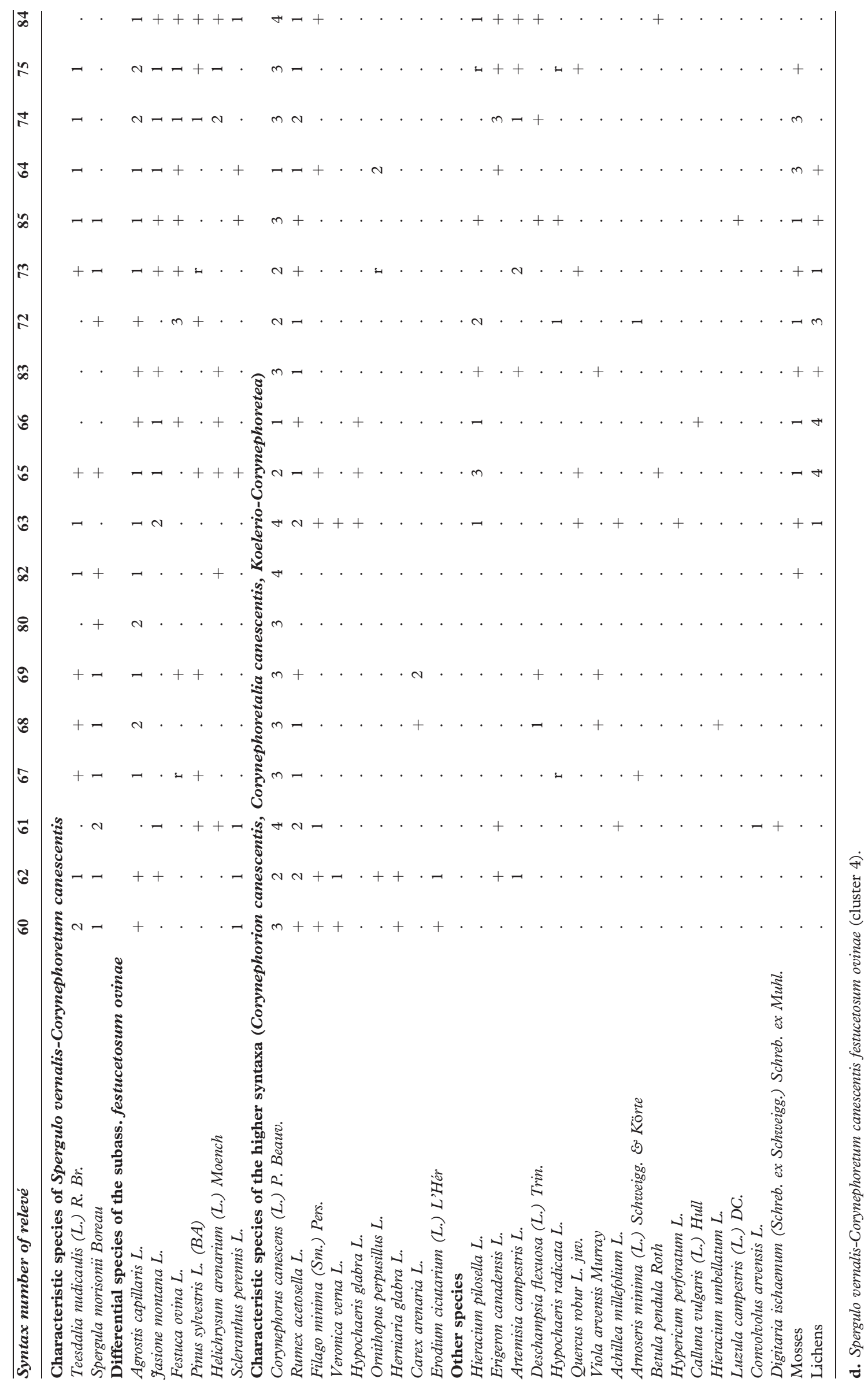




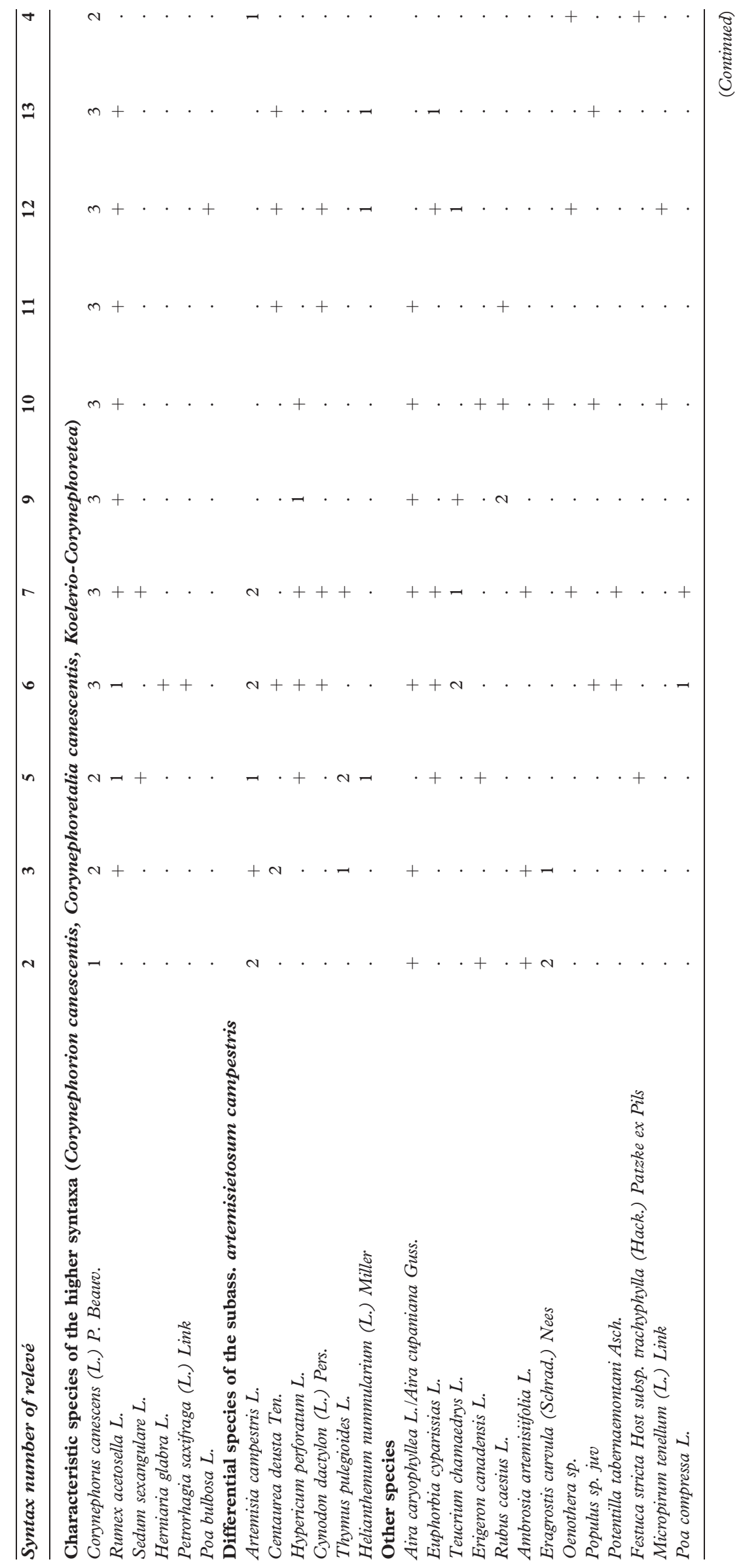




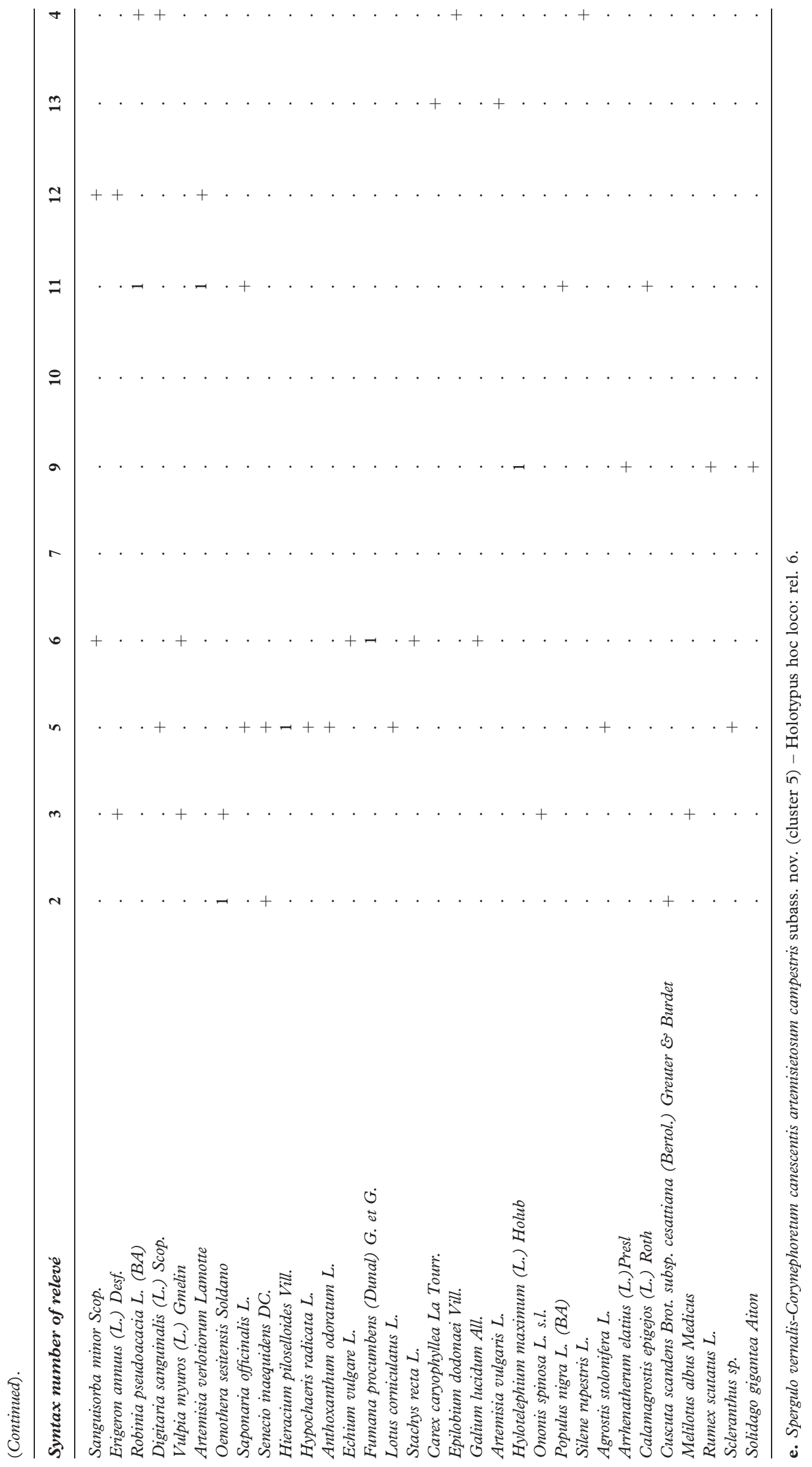




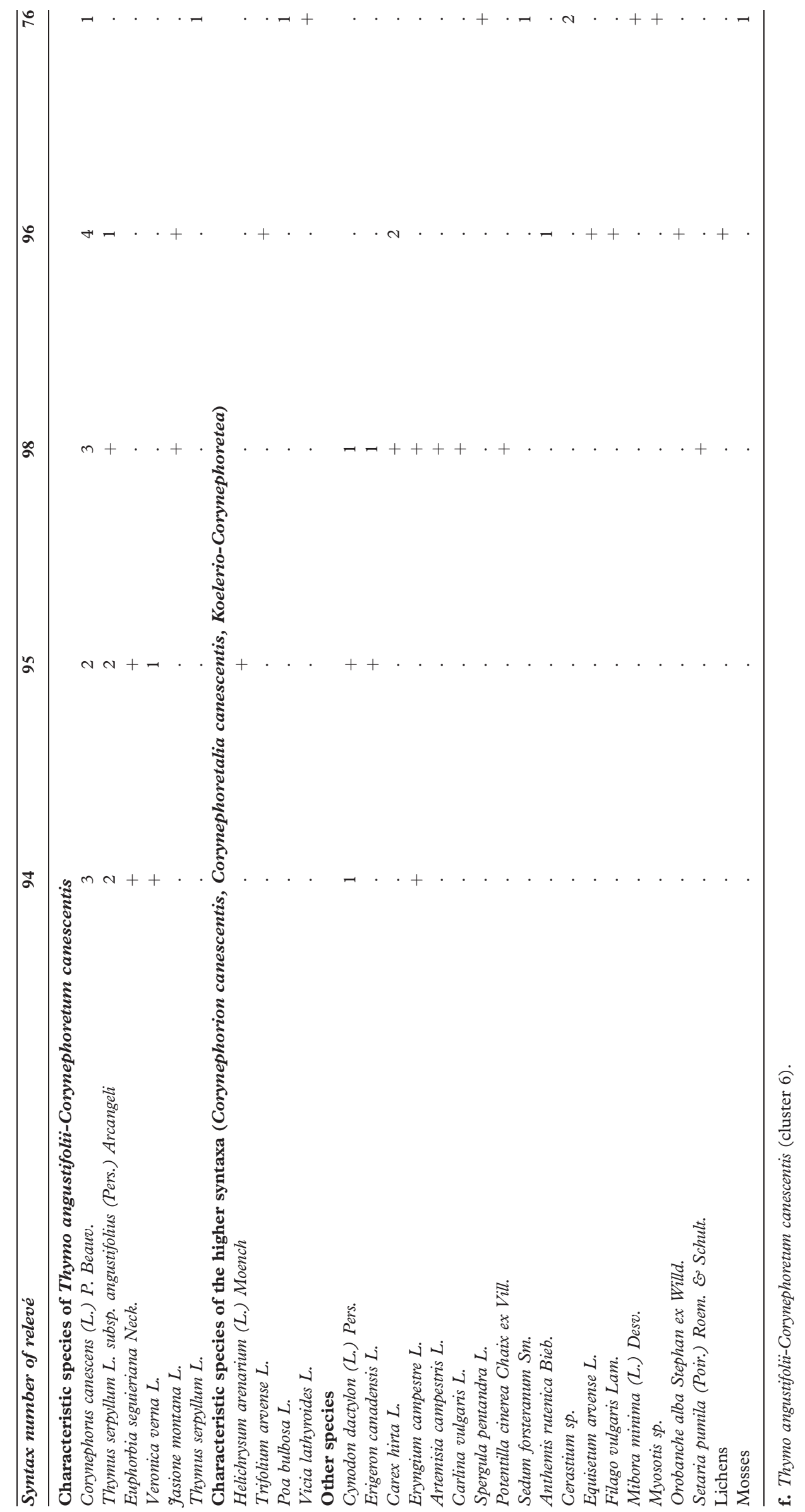




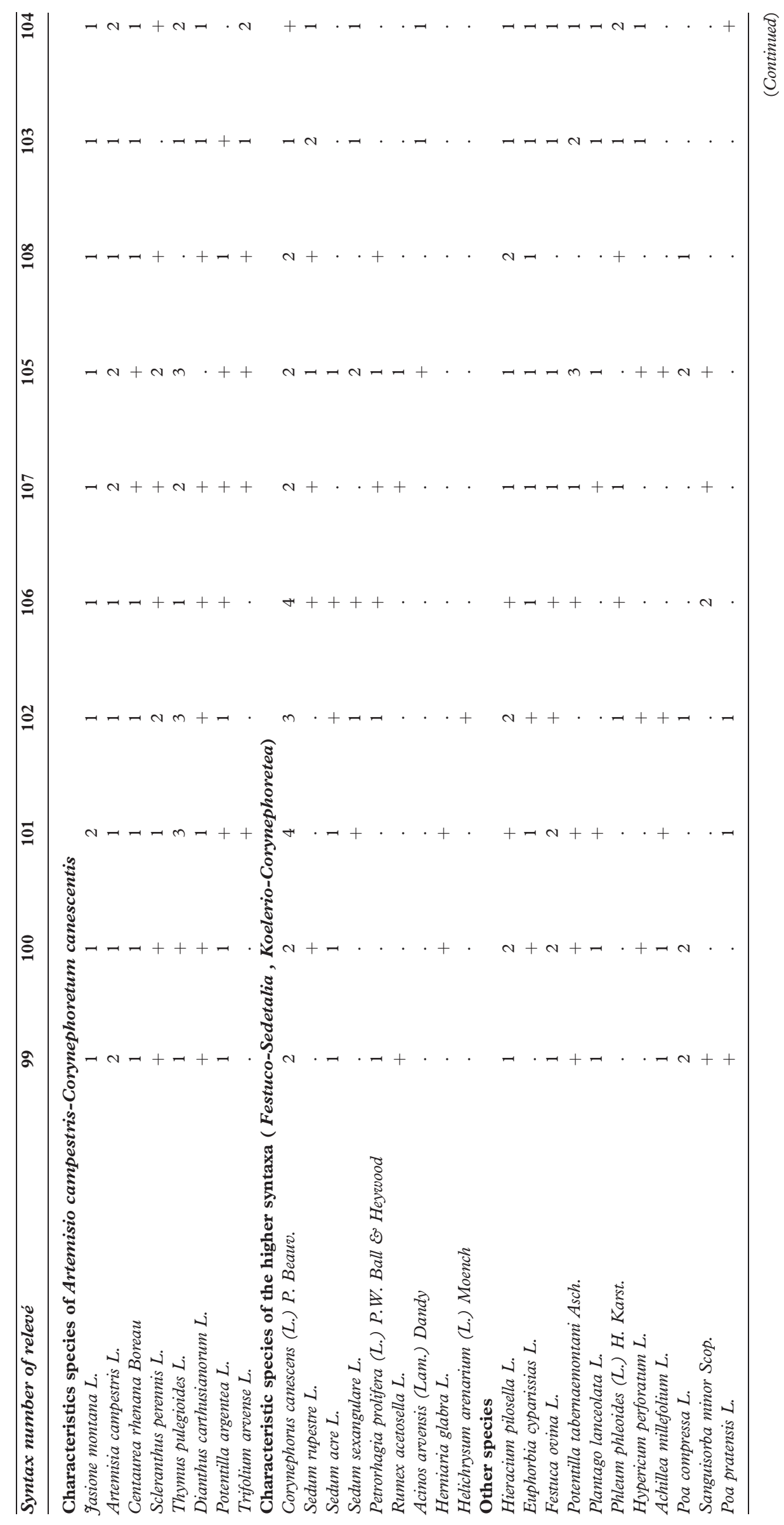




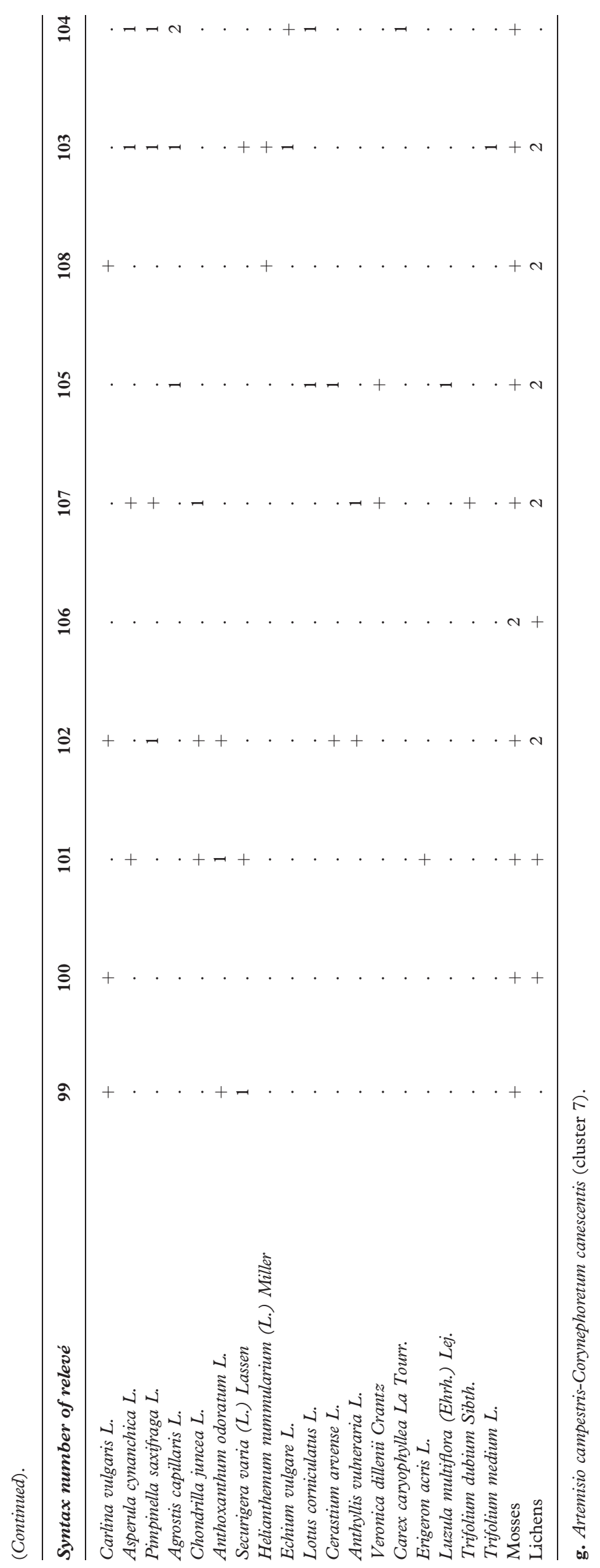




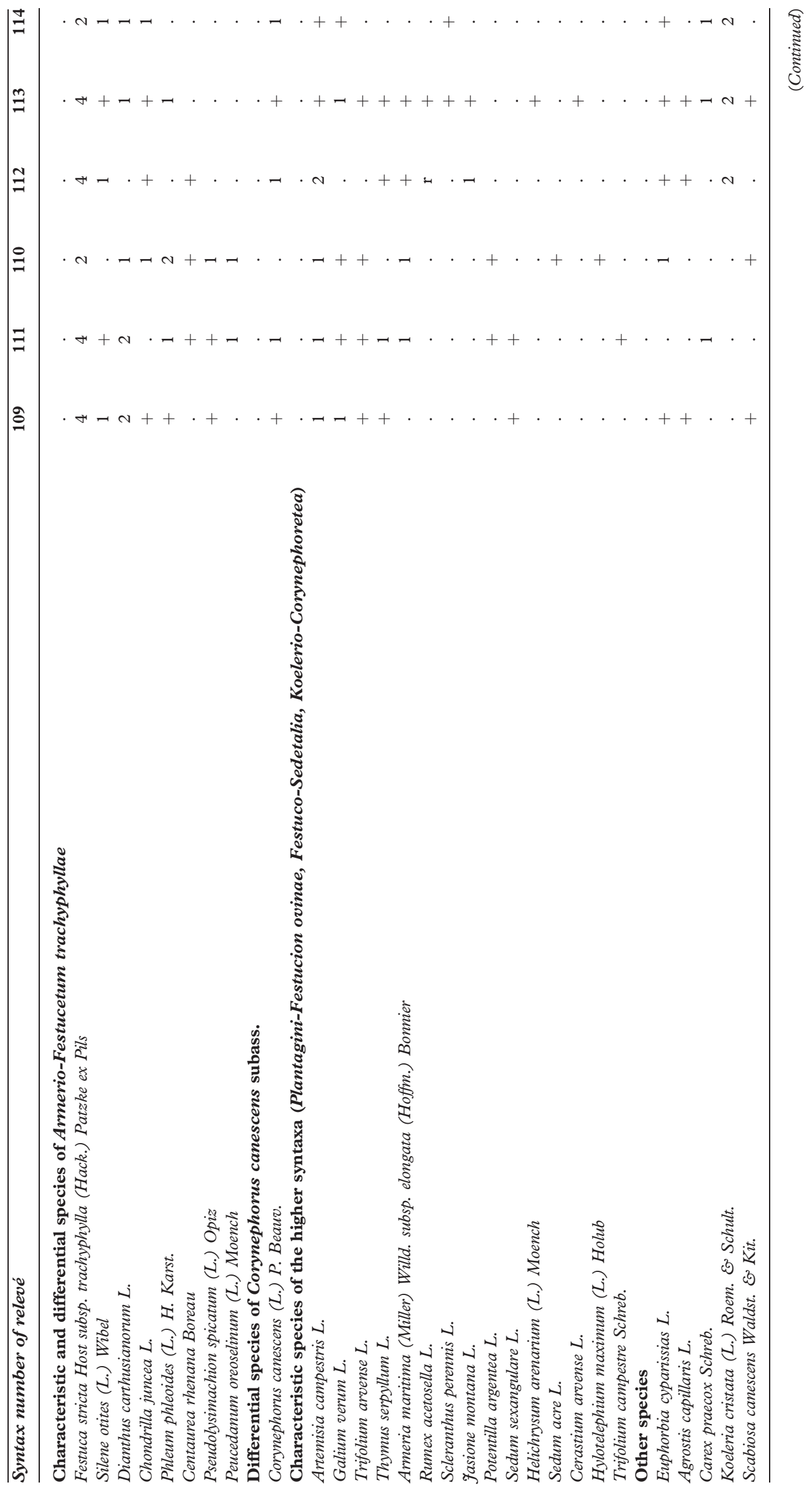




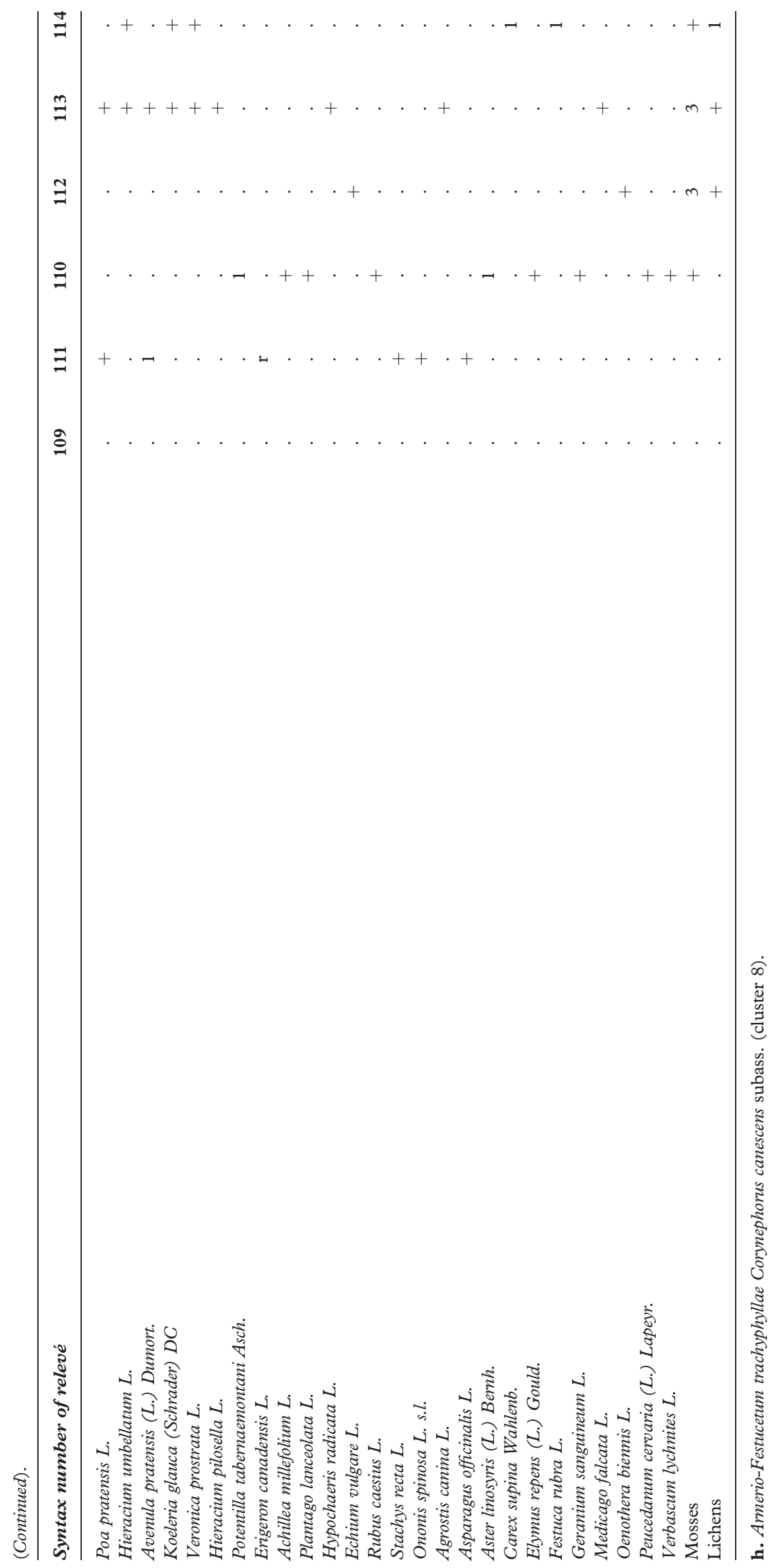

